\title{
BİR HİDROLİK DERİN ÇEKME PRES MAKİNESINIIN PLC TABANLI BULANIK MANTIK KONTROLÜ VE ENDÜSTRİ 4.0 UYGULAMASI
}

\author{
1Ömer AYDOĞDU, ${ }^{2} \mathrm{Ahmet}$ ÇATKAFA \\ ${ }^{1}$ Konya Teknik Üniversitesi, Mühendislik ve Doğa Bilimleri Fakültesi, Elektrik - Elektronik Mühendisliği Bölümü, \\ Konya, TÜRKIYE \\ 2SECA Mühendislik Otomasyon Ltd. Şti., Konya, TÜRKIYE \\ ${ }^{1}$ oaydogdu@ktun.edu.tr, 2ahmetcatkafa@gmail.com
}

(Geliş/Received: 16.01.2019; Kabul/Accepted in Revised Form: 18.02.2019)

\begin{abstract}
ÖZ: Bu makalede bir derin çekme pres makinesinin PLC tabanlı bulanık mantık kontrolü gerçekleştirilmiştir. PLC ortamında Bulanık Mantık Denetleyiciler için bulanıklaştırma, çıkarım işlemi ve durulaştırma adımları ayrı bloklar olarak gerçekleştirilmiş, blokların program dâhilinde yürütülmesi ile kontrol işlemi gerçekleştirilmiştir. PLC ortamında gerçekleştirilen bulanık mantık kontrol programı, derin çekme pres makinasında uygulanmış ve karşılaştırma amaçlı sonuçlar elde edilmiştir. Ayrıca hidrolik derin çekme pres makineleri için Endüstri 4.0 kavramı incelenmiş, mevcut sistemlerle karşılaştırılması yapılmış ve mevcut sistemlerin Endüstri 4.0'a uyumları ele alınmıştır. Çalışmada, proje kapsamında iki farklı hidrolik derin çekme pres makinesi ele alınmıştır. Bunlardan biri klasik olarak kontrol edilen AC motor tahrikli sabit devir ve debide olan hidrolik güç ünitesi ile çalışan bir prestir. Diğer makine ise servo motor tahrikli değişken debili hidrolik pompanın bulunduğu hidrolik güç ünitesi ile çalışan sistemdir. Bu iki sistem arasında belirli özellikler için kıyaslama yapılarak Endüstri 4.0 uyumu ve üstünlüğü somutlaştırılmaya çalışılmıştır.
\end{abstract}

Anahtar Kelimeler: Bulanık Mantık, PLC, Derin Çekme Pres Makinesi, Hidrolik Pres, Servo Pres, Endüstri 4.0

\section{PLC Based Fuzzy Logic Control Of A Hydraulic Deep Draw Press Machine}

\begin{abstract}
In this article, PLC based fuzzy logic control of a deep drawing press machine has been realized. In the study, blurry, inference process and clearing steps were carried out as separate blocks for Fuzzy Logic Controllers in PLC environment. Fuzzy logic control program implemented in PLC environment was applied on deep drawing press machine and comparison results were obtained. In addition, the concept of Industry 4.0 has been examined for hydraulic deep-drawing press machines, compared with existing systems and the compliance of existing systems with Industry 4.0 has been discussed. In this study, two different hydraulic deep drawing press machines are discussed. One of them is a conventional prestressed AC motor driven station with a constant speed and flow rate hydraulic power unit. The other machine is a hydraulic power unit with servo motor driven variable flow hydraulic pump. A comparison between these two systems has been made for specific features, and the convergence and superiority of Industry 4.0 has been tried to be concretized.
\end{abstract}

Keywords: Deep Drawing Press Machine, Fuzzy Logic, Hydraulic Press, Industry 4.0, Servo Press, PLC

\section{GİRIŞ̧ (INTRODUCTION)}

Hidrolik pres makineleri, bir elektrik motoru yada servo motor tahrikiyle çalıştırılan hidrolik pompanın, hidrolik bloğa basmış olduğu belirli basınç ve debideki hidrolik yağ ile çalışan endüstriyel 
araçlardır. Hidrolik blok üzerindeki valflere hidrolik güç ünitesinin elektrik mantık diyagramına göre enerjinin belirli bir sırada verilmesiyle blok hatlarından geçen basınçlı hidrolik yağ, pres makinesinin koç ve pot tablalarının silindirlerine ulaşır. Silindirlerin pistonlarını hareket ettirerek tablaların hareketi sağlanmış olur. Silindirlere gönderilen yağ miktarı ve basıncı kontrol edilebildiği için presin aşağı yukarı hızları ve tonajı istenen değerlerde ayarlanabilir. Bu özelliklerden dolayı özellikle derin çekme kalıplarında Şekil 1'de görüldüğü gibi hidrolik presler kullanılır.

Hidrolik preslerin en belirgin özelliği her vuruşta aynı kuvveti uygulamaktır. Şekillendirme presinin ihtiyacı olan gücü üreten değişken hızlı pompa, tahrik sistemlerini içerecek hidrolik güç ünitesi, hidrolik pompa, kontrolör ve servo motordan oluşan kapsamlı bir sistemi içermesinin yanı sıra çevrim karakteristiğine ve yapılandırmasına dayanan bir yazılımdan oluşmaktadır. Bu sistem, basınç ve debi kontrol sistemini temel almaktadır.

Bu çalışmada, bir servo sürücü kullanılarak, sistem yağ hacmini ve basıncını kontrol etmek için dinamik ve çok ekonomik bir çözüm ortaya konulmuştur. Ayrıca, yeni tasarlanan hidrolik üniteden elde edilen verilerin karşılaştırılması için klasik sistemle yapılmış bir hidrolik güç ünitesi de çalıştırılmış ve deneysel test verileri elde edilmiştir (Bostan, 2011).

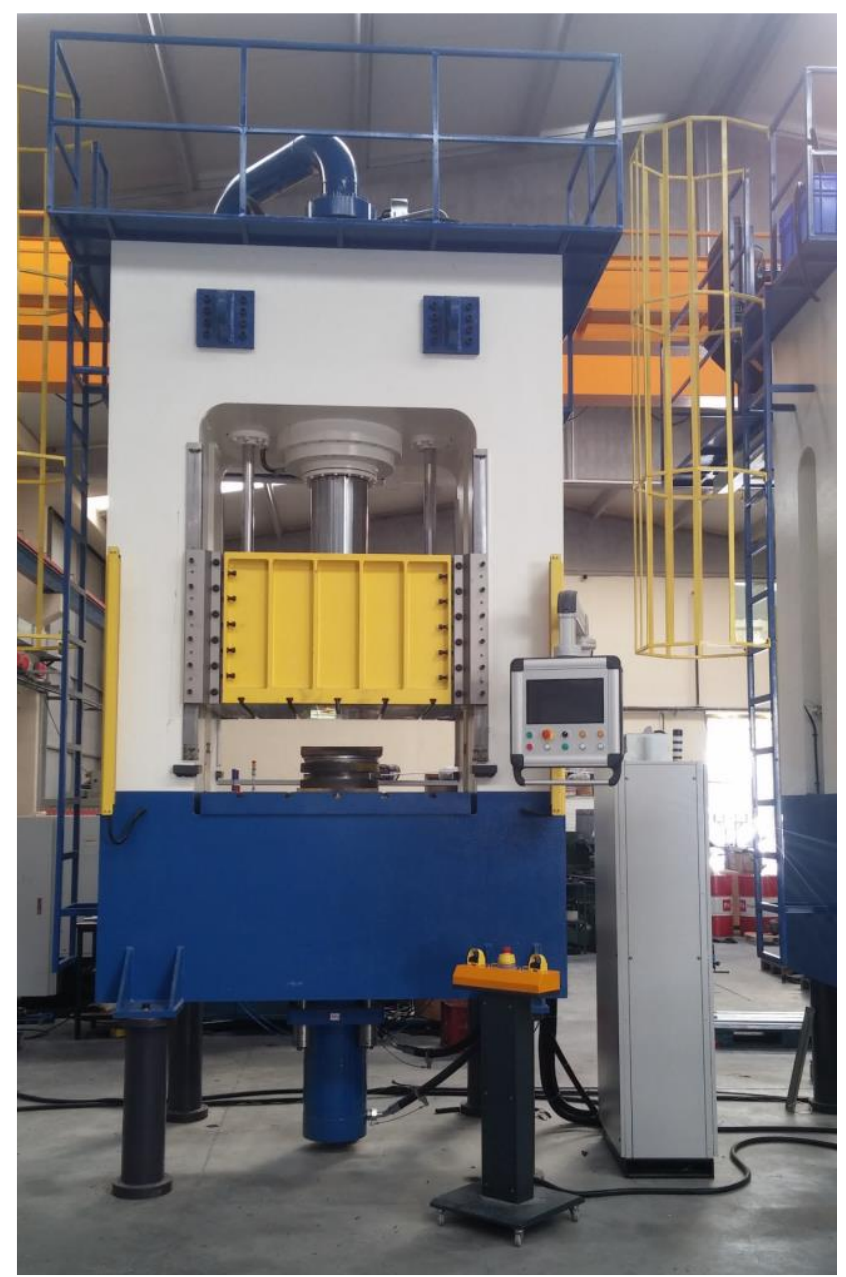

Şekil 1. Hidrolik derin çekme presi

Figure 1. Hydraulic deep drawing press

Endüstriyel bir sürecin denetimi için tasarım yapılırken her şeyden önce o sürecin bir dinamik modeline gereksinim vardır. Ancak pratikte bu her zaman mümkün olmayabilir. Süreç içerisindeki olaylar matematiksel modellemeye el verecek ölçüde açıkça bilinmeyebilir veya bir model kurulabilse bile bu modelin parametreleri zamanla değişiklikler gösterebilir (Yılmaz, 1999). Bazı durumlarda ise doğru model kurulsa bile bunun denetleyici tasarımında kullanılması karmaşık problemlere yol açabilir. 
$\mathrm{Bu}$ gibi sorunlarla karşılaşıldığı zaman genellikle uzman bir kişinin bilgi ve deneyimlerinden yararlanılma yoluna gidilir (Özçalık, 2008). Uzman kişi dilsel niteleyiciler (linguistic variables) olarak tanımlanabilecek; uygun, çok uygun değil, yüksek, fazla, çok fazla gibi günlük yaşantımızda sıkça kullandığımız kelimeler doğrultusunda esnek bir denetim mekanizması geliştirir. İşte bulanık mantık denetim de bu tür mantıksal ilişkiler üzerine kurulmuş bir yaklaşımdır (Zadeh, 1971).

Bulanık mantığın sağladığı en büyük fayda ise "insana özgü tecrübe ile öğrenme" olayının kolayca modellenebilmesi ve belirsiz kavramların bile matematiksel olarak ifade edilebilmesine olanak tanımasıdır (Sinecen, 2002). Bu nedenle doğrusal olmayan sistemlere yaklaşım yapabilmek için özellikle uygundur. Bunun için kural tabanı oluşturulur. Kural tabanı incelenen konuya ilişkin insanlı̆̆ın o güne kadar edindiği tüm gözlem, deneyim ve matematiksel bağıntıları yani tüm bilgiyi içermelidir. Kural tabanı ne kadar iyi ve geniş hazırlanırsa o kadar hassas ve doğru sonuçlar elde edilir (Saad, 2012). Bulanık mantık, fotoğraf makineleri, çeşitli elektronik beyaz eşyalar, füzeler, robotlar, otomasyon ve akıllı kontrol sistemleri, akıllı bina sistemleri ve otomatik iletim hatları gibi uygulamalarda sıkça kullanılmaktadır (Da Ruan, 1998). Bu avantajlar dikkate alındığında, bir hidrolik derin çekme pres makinasının bulanık mantık kontrolü ile, sistemin kararlılığı ve enerji tasarrufu sağlayacağ öngörülmektedir. Çalışmada bu doğrultuda, bir PLC elemanı kullanılarak girişine gelen geri besleme bilgisini bulanık mantık kontrol algoritması ile işleyerek kontrol çıkışını güncelleyen bir kontrol donanımı tasarlanmıştır. Böylece, derin çekme pres makinalarında daha hassas ve daha kararlı bir çalışma amaçlanarak, sistemin daha verimli hale gelmesi sağlanacaktır.

Endüstri 4.0 kavramı, otomasyona yönelik sistemlerin saha sensörleri ve uç birimlerinden gönderilen verilere ve gelen verilerin işlenmesine dayanmaktadır. Endüstri 4.0 yaklaşımı ile, otomasyon sistemleri mevcut çalışma koşulları, performansı ve elde ettiği sonuçlar olarak sürekli ölçümlenmektedir. Toplanan veri, endüstriyel standartlarda veri aktarımına uygun ve yüksek güvenlikli iletişim sistemleriyle büyük veri merkezlerine iletilmektedir. Ardından, bu veriler yüksek performanslı analiz sistemleriyle anlamlı verilere ve somut aksiyonlara dönüştürülmektedir. Böylece; sistemlerin verimliliğini artıracak yeni yaklaşımların uyarlanması, sorun çıkaran bir bileşenin devre dışı bırakılarak iş yükünün diğer bileşenlere aktarılması gibi süreçlerin hepsi otomatik olarak gerçekleştirilmektedir (Kaynak, 1993). Yani, makineler ve sistemler kendi kendini yeniden ayarlamakta, kendi çalışmasını optimize etmekte, hatta yapay zekayı kullanarak yeni sorunlara yeni çözümler üretmektedir. İnsanların yerine karar vermekte ve uygulamaktadır (Kılıç, 2017). Bu, gelişen teknoloji yardımıyla kendi elde ettiği verileri kullanarak kendi süreçlerini yeniden düzenleyebilen, kendi çözümünü kendi üreten ve kendi kendini optimize eden makinelerin yer aldığı bir süreçtir (Selek, 2017). Bu çalışmada ayrıca, Hidrolik Derin Çekme Pres Makinesi (Hydraulic Deep Draw Press Machine) için Endüstri 4.0 uygulanabilirliği ele alınarak, avantajları ortaya konulacaktır.

\section{PLC TABANLI BULANIK MANTIK KONTROL (PLC BASED FUZZY LOGIC CONTROL)}

Bulanık mantık kontrol, Şekil 2'de görüldüğü gibi beş temel bileşenden oluşur. Bunlar; ölçekleme, bulanıklaştırma, bulanık bilgi ve kural tabanı, çıkarım birimi ve durulaştırmadır (Altaş, 1999). Bulanık mantık denetim işlemi optimum çıkışı elde etmek için genel olarak giriş bilgilerinin 0-1 aralığında bulanık küme (set) değerlerine dönüşmesiyle başlar. Daha sonra bilgi tabanına göre gerekli çıkarımlar sağlanarak oluşturulan kural tabanına göre uygun çıkış için bulanık küme (set) değerleri oluşturulur. En sonunda bu bulanık set değerlerinden durulaştırılmış kontrol çıkışı elde edilir (Özdemir, 2012).

Bulanık sistemde bilgi tabanı, karar verme biriminin kural tabanında da kullanılan bilgileri aldığı veri tabanı (data base) ve denetim amaçlarına uygun dilsel denetim kurallarının bulunduğu kural tabanı (rule base) olmak üzere iki kısma ayrılabilir (Aydoğmuş, 2009). Genel olarak da uygulama dönemindeki bilgilerden ve denetim amaçlarından oluşur. Bilgi tabanından dilsel denetim kurallarının tanımlanmasında ve bulanık mantık denetimindeki bulanık bilgi işleme süresince yararlanılır. Kurallar kümesi denetimin amaçlarını, sürecini ve stratejisini belirler. Denetimi yapılan sistemle ilgili, bulanıklaştırma (fuzzification), bulanık çıkarım, durulaştırma (Defuzzification) işlemleri sırasında gerek 
duyulan üyelik işlevi ve kural çizelgesi bilgileri veri tabanından (data base) kullanıma sunulur (Elmas, 2007).

Yapılan çalışmada asenkron motor tahrikli hidrolik pompa ile çalışan standart hidrolik pres makinesi incelenmiş ve sistem basıncı üzerinde oluşabilecek değişiklikleri olabildiğince minimum seviyelere çekerek sistemin daha optimum bir şekilde bulanık mantık denetleyici kullanılarak çalıştırılması hedeflenmiştir. Hidrolik pres makinelerinde optimum iş yapılabilmesi için sistem basıncının her bir çevrimde sabit kalması gerekmektedir. Basıncın çok küçükte olsa sabit kalmama nedenleri arasında sistemdeki 1sı kayıpları, basıncın oluştuğu bölümlerdeki mekanik kayıplar, sistem basıncının ölçüldüğg̈ transmitterin ölçüm hassasiyeti yada PLC'den gerekli analog sinyalin gönderildiği basınç oransal valflerinin çalışma hassasiyetleri gösterilebilir. Uygulama üzerinde PLC'nin BM modülünü kullanarak ilgili parametre ayarları ile modül aktif edilip PLC içerisine yazılan yazılımla bu işlem gerçekleştirilebileceği gibi, BM modülünü kullanmadan PLC içerisinde BM kontrol modellemeleri yaparak da daha kompleks bir yazılım ile basınç kontrolü sağlanabilir. BM kontrol modelleme tercih edilmesinin avantajları; genel kontrol algoritması, hızlı tepki vermesi ve en optimum karar alınması olarak siralanabilir (Karakuzu, 2013).

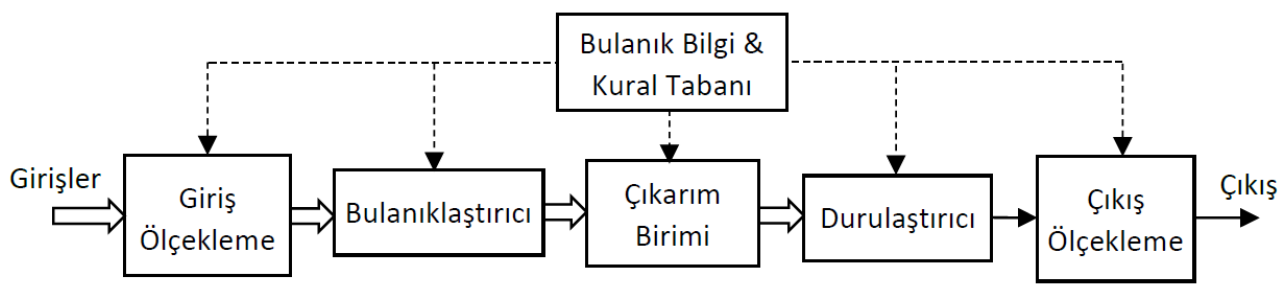

Şekil 2. Bulanık mantık kontrol temel yapısı

Figure 2. Fuzzy logic control basic structure

Çalışmada, hidrolik derin çekme pres makinesinin mekanik aksamı tasarlandıktan sonra Şekil 3'de gösterilen elektrik panosunda yer alan PLC içerisinde bulanık mantık kontrol yazılımı geliştirilmiştir. Makine üzerindeki hidrolik güç ünitesinde hidrolik blok yer almaktadır. Bu hidrolik blok üzerinde yer alan ve bulunduğu hattın basıncını ölçen basınç transmitterinden alınan analog sinyal, PLC içerisinde yazılan bulanık mantık kontrol ile işlenmiştir. İşlenen bu sinyal daha hızlı ve daha kararlı bir şekilde analog bir sinyale dönüştürülerek blok hattına basıncı sağlayan oransal valf kartına verilmiştir. Böylece kapalı çevrim bulanık mantık kontrol sistemi amaçlanmıştır. Kapalı çevrim bulanık mantık kontrol sisteminde, klasik sistemdeki basınç kontrolüne göre daha hassas ve sistem basıncının olması gereken stabil değerleri, operatörün panelden girerek istemiş olduğu sistem basınç değerlerine daha yakınlık göstermiştir. PLC, girişinden okumuş olduğu analog sinyali kendi içerisindeki yazılımla çıkışına daha kararlı bir şekilde aktardığı gözlemlenmiştir. Böylece ortaya çıkacak ürünün daha düzgün olması için gerekli basınç ve tonaj değeri ne ise sistem daha kararlı sağlamıştır. Sistemin istenen basıncı birebir aynı değeri verememesi, basınç verici (transmitter) ve oransal valf kartının ölçüm hassasiyetlerinden ve sistemdeki kayıplardan kaynaklanmaktadır. 


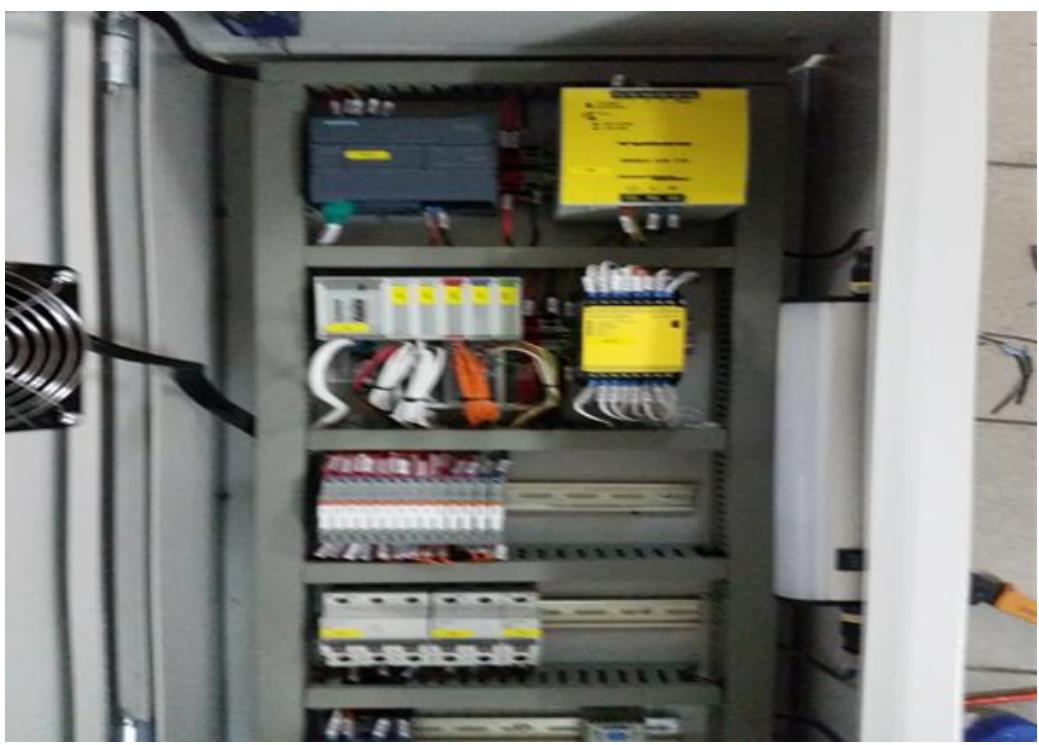

Şekil 3. Hidrolik pres elektrik kontrol panosu

Figure 3. Hydraulic press electrical control board

Şekil 4'de bulanık mantık kontrol algoritmalarının yürütüldüğü PLC tabanlı bulanık kontrol sistemi blok şeması görülmektedir. Input-1 (I1) sistemin basıncı ( Koç Tabla Basıncı )'nı ölçen ve çıkışında analog bir sinyal veren basınç verici, Output-1 (O1) ise girişine gelen analog sinyale göre basıncın uygulanmasını sağlayan basınç oransal valf ve kontrol kartını göstermektedir.

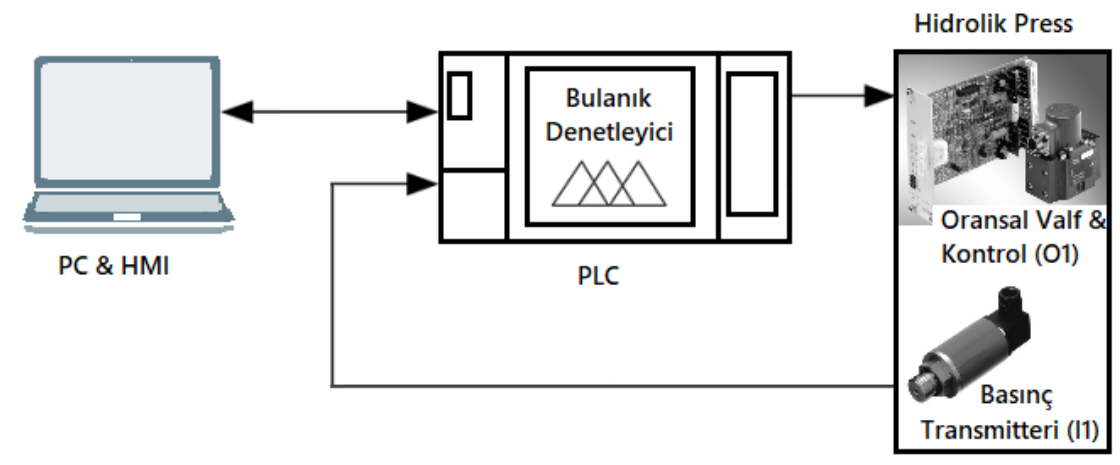

Şekil 4. PLC tabanlı bulanık kontrol sistemi

Figure 4. PLC based fuzzy control system

Sistem operatör HMI ekranından çalıştırıldıktan sonra pres makinesi yapması gereken işlevi gerçekleştirirken I1 basınç sensöründen okunan analog sinyal PLC'de bir dizi içerisinde kaydedilir. PLC'de yer alan BM kontrollü program devreye girer. Şekil 5'de blok diyagramları verilen Min-Max yöntemi ile okunan basınç değerlerinin minimum ve maksimumları tespit edilmiştir.

PLC analog modül çıkışına verilecek olan sinyalin minimum ve maksimumları yine Şekil 5'te gösterildiği gibi program tarafından tespit edilir. Tespit edilen çıkış değerleri program içerisinde Şekil $6^{\prime}$ da gösterildiği gibi ağırlık ortalaması fonksiyonuna tabi tutularak çıkışa verilmesi gereken en uygun çıkış yüzdesi bulunur. Şekil 7'de bulunan çıkış yüzdesi değerine göre oransal valf kartına ne kadarlık bir analog sinyal uygulanması gerektiğine PLC karar verir. 

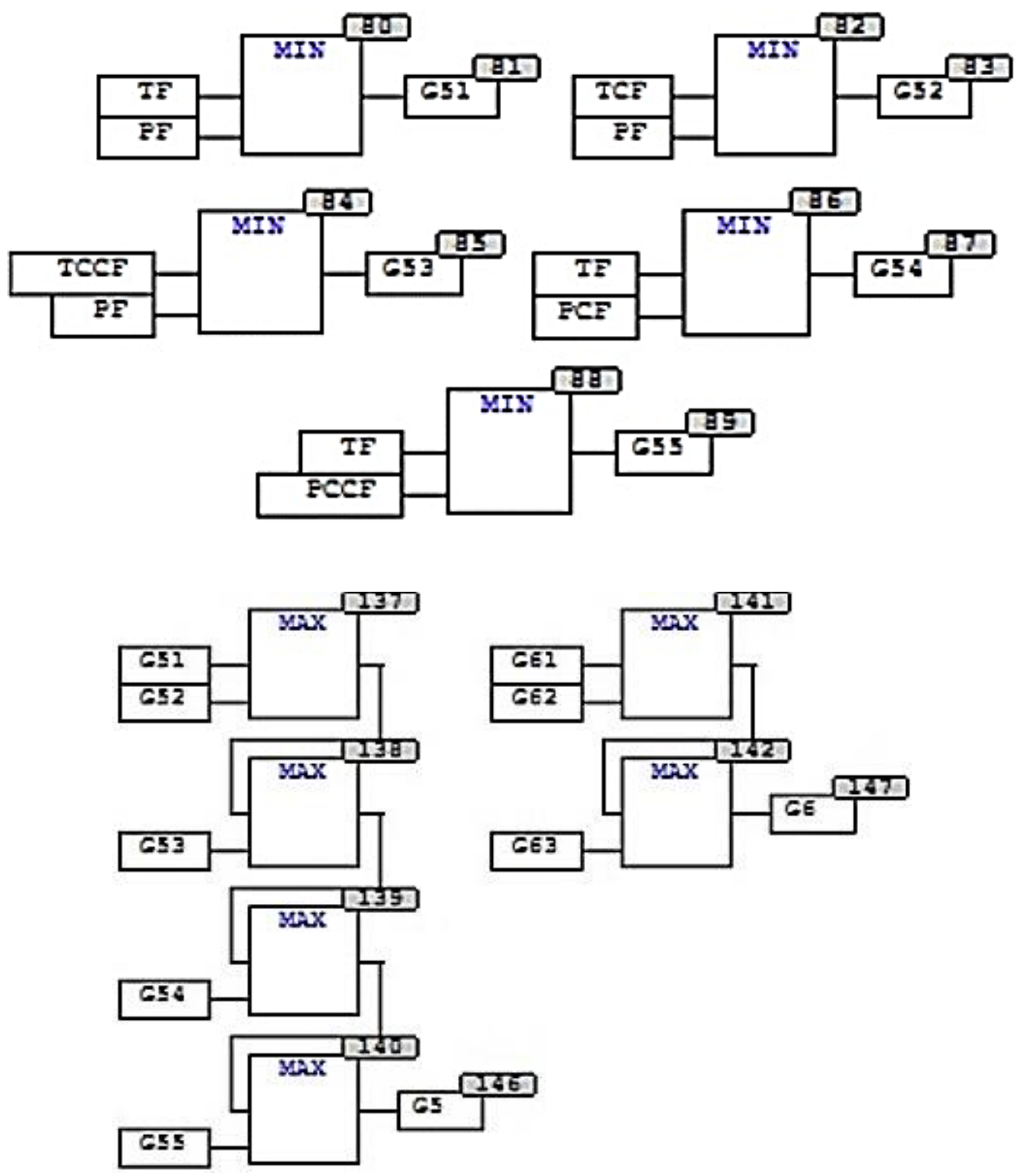

Şekil 5. PLC yazılımında min-max çıkarım işlemi

Figure 5. Min-max inference process in PLC software

\section{HIDROLİK PRES MAKİNELERINNDE ENDÜSTRI 4.0 UYGULAMASI (INDUSTRY 4.0 APPLICATION IN HYDRAULIC PRESS MACHINES)}

Klasik hidrolik sistemler ile servo tahrikli hidrolik sistemleri karşılaştırmak üzere iki farklı preste hidrolik üniteler birim zamanda yapılan iş ve enerji sarfiyatı ölçümü için çalıştırılmıştır. Birim zamanda çıkan iş parçası sayısı, harcanan güç, oluşan gürültü, yağ sıcaklığı ölçümleri yapılarak, elde edilen verilere göre verimlilik hesapları yapılmıştır. Servo motor tahrikli değişken hızlı pompa ile çalışan hidrolik güç ünitesi ile yüksek enerji tasarrufu, verimlilik sayesinde, hidrolik sistemin güç tüketiminde $\% 13,98$, ortam gürültüsünde $\% 6$ düşüş elde edilmiş, \%18'lik daha fazla üretim yapılabileceği gözlemlenmiştir. Ayrıca daha az sıcaklık girdisinden dolayı da hidrolik sistemin çalışma ömrünün artması da beklenmektedir. Böylece Endüstri 4.0'a uygun bir şekilde sistem hassasiyeti arttırılmış olup ve yüksek bir enerji tasarrufu sağlanmıştır. Servo motorlu sistemin klasik sisteme göre daha düşük desibel seviyelerinde çalışması sağlanmıştır. 


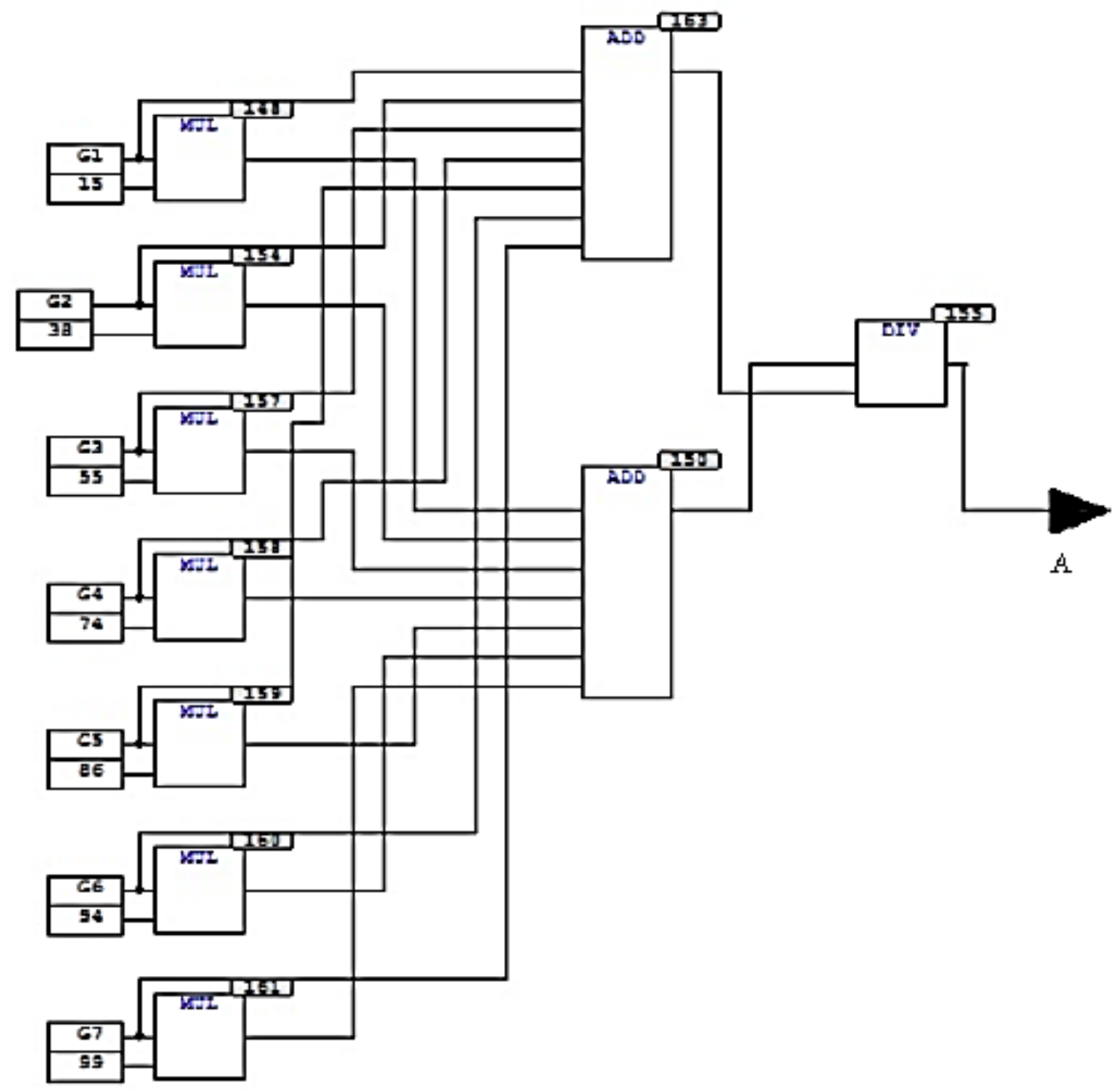

Şekil 6. PLC içinde ağırlık ortalaması ile durulaştırma bloğu

Figure 6. Defuzzification with weight mean in PLC

Her iki sisteme de Endüstri 4.0'ın en önemli uygulamalarından biri olan RFID teknolojisi entegre edilebilir durumdadır. Böylece makine Endüstri 4.0'a uygun bir şekilde kendi kendine algılama, karar verebilme, ve gerekli doneleri yazılan yazılımla kendi içerisinde sağlayabilmektedir.

Endüstri 4.0'ın en önemli uygulamalarından biri olan RFID teknolojisi radyo frekanslarıyla çalışan elektronik olarak tanımlama sistemleridir. Bu sistemlerin okuma-yazma kafası ve etiket olarak iki önemli bileşeni vardır. Böylece preste şekillendirilecek ürünün cinsi, karakteristiği ne olursa olsun etiket (tag) adını verdiğimiz sistem bileşenleriyle okuma-yazma kafasından okunan ürün bilgisi sistemdeki PLC'ye tanıtılarak ürünün veya kalıbın şekillendirilmesi için gerekli olan basınç ve tonaj değerleri yazılım sayesinde hesaplanabilir duruma getirilmektedir. Böylece makine endüstri 4.0'a uygun bir şekilde kendi kendine algılama, karar verebilme ve gerekli doneleri yazılan yazılımla kendi içerisinde sağlayabilmektedir.

Endüstri 4.0'ın en önemli bileşenlerinden biri de IO-Link'tir. IO-Link otomatik olarak sensörleri parametrelerle ifade etme, tesis durumlarının tanısı ve değerlerin ölçümünde kayıpları önleyerek aktarma görevi bulunan noktadan noktaya dağıtılan seri iletişim protokolüdür. Böylece daha kolay ve daha hızlı iletişim kurmak için ve global olarak tercih edilen bir çözüm yolu olmuştur. Pres makinesi üzerindeki hidrolik güç ünitesinde yer alan bazı elektronik cihazlar IO-Link özellikli seçildiğinde, operatörün kullanacağı endüstriyel akıllı tablet pc ekranına yüklenen özel parametrelendirme arayüz 
programları sayesinde parametre ayarları yapılabilir duruma gelmektedir. Böylece, IO-Link özellikli cihazlar olması sebebiyle hataların olabildiğince minimize edilmesi, sistemde algılanan verinin çok daha hızlı bir şekilde işlenerek sinyal olarak aktarılması söz konusudur.

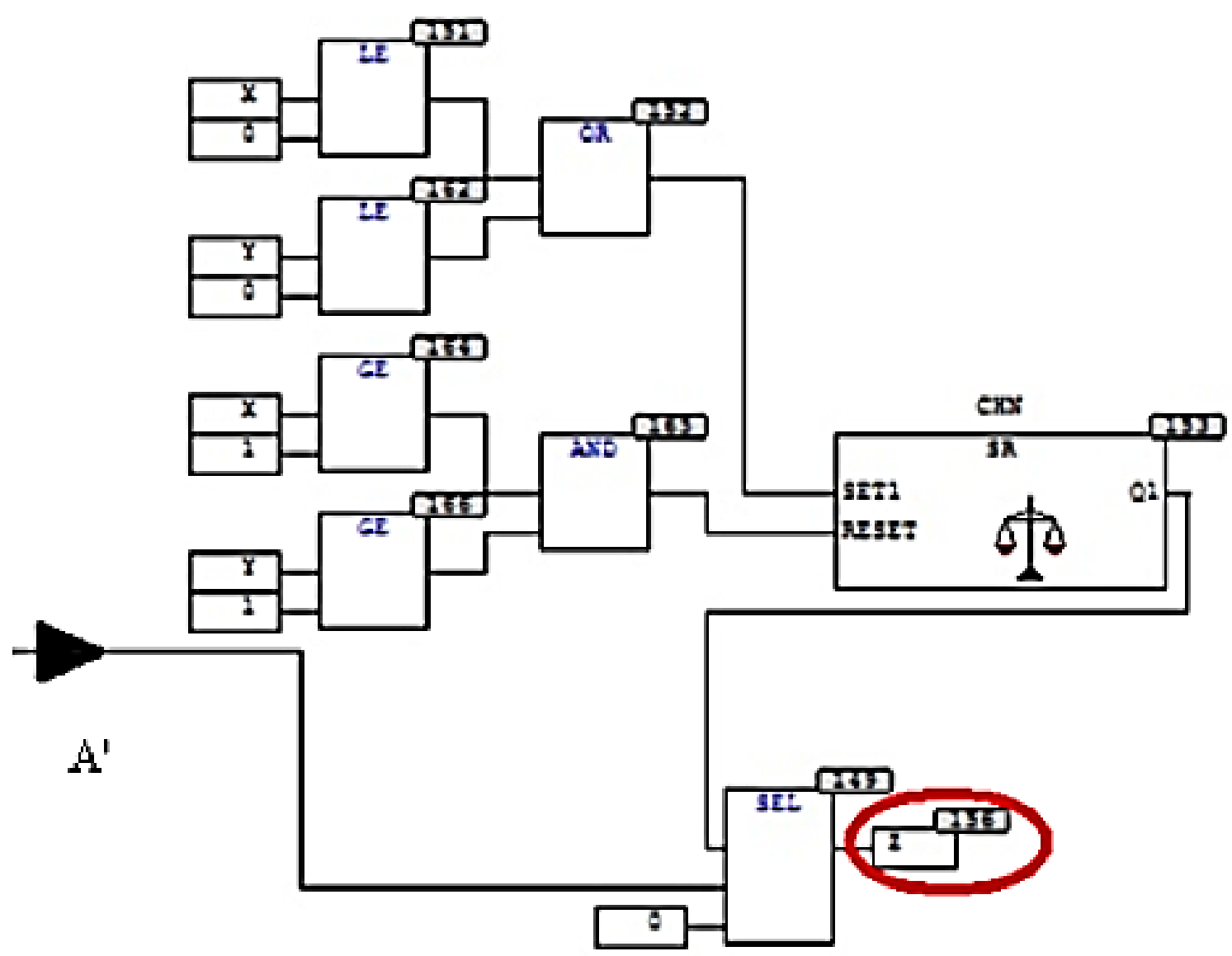

Şekil 7. PLC içinde bulanık mantık kontrol çıkışı

Figure 7. Fuzzy logic control output in PLC

Elektrik motorunun üzerine yerleştirilebilir durumda olan titreşim-sıcaklık sensörü sayesinde motor, mekanik arızalardan ve bundan dolayı oluşabilecek can ve mal kayıpları, diğer arıza gibi süreçlerden korunabilir durumdadır. Kestirimci-Bakımcılık sayesinde motorun anlık olarak mekanik durumu ve sıcaklığıyla alakalı bilgiler alınıp işlenebilir durumdadır. Sensörün ayarlanan değerlerine yakın değerlerde, sensör ilgili çıkışlarını üreterek operatöre alarm verebilir durumdadır. Böylece sistem tehlikelere karşı korunmuş olacaktır. Ayrıca makine de beklenmeyen ve istenmeyen durumlar yaşanmayıp ciddi iş potansiyel kaybı ve mali kayıpların önüne geçilmiş durumdadır. Bu durumda Endüstri 4.0 için önem arz etmektedir. Sonuç olarak klasik hidrolik sistemlerin yerini artık Endüstri 4.0'a uygun servo tahrikli hidrolik sistemlerin alacağı görülmektedir.

\section{DENEYSEL SONUÇLAR (EXPERIMENTAL RESULTS)}

Çalışmada, deneylerin yapılabilmesi için öncelikle özel bir firma tarafından üretilen, boyut ve kullanılan malzeme bakımından aynı özelliklere sahip iki adet hidrolik pres makinesinden yararlanılmıştır. Aynı şekilde bu pres makineleri için üretilen, ve şaselerin üst kısmına montaj edilen iki adet hidrolik güç ünitesi denemeler için kullanılmıştır. Kullanılan hidrolik güç ünitelerinde, pompalar ve onları tahrik edici motorlar, servo motor ve asenkron motor olarak birbirinden farklıdır. Ayrıca 
pompalar, sabit debili ve değişken debili pompa olarak kullanılmış olup hidrolik güç ünitesinin diğer kullanılan malzemeleri ve boyutları aynıdır. Her iki sisteminde çalıştırılması için ihtiyaç duyduğu elektrik tesisatı oluşturulup panoları yapılmıştır. Gerekli kontroller yapılıp makineler devreye alındıktan sonra her iki sistemde deneylerin yapılmasına hazır hale gelmişlerdir.

Deneye başlamadan önce ilk olarak Çizelge 1'de görüldüğü gibi koç ve pot tablalarının her iki makinede hızlı iniş, presleme ve sıvama aşamalarındaki toplam katetmesi gereken mesafeler endüstriyel PC üzerinden sisteme yüklenmiştir. Burada hedef, tablaları aynı mesafede çalıştırarak zaman kaybı olmadan aynı süreleri elde edip bu süreler içerisinde tükettikleri enerji miktarlarını tespit etmektir. Yine aynı çizelgede dikkat edileceği gibi koç ve pot tablalarının basınç değerleri ve makinelerin toplam çalışma iş adetleri aynı tutulup, tabla mesafelerinde olduğu gibi Endüstriyel PC üzerinden sisteme yüklenmiştir. Böylece her iki sistemde de makinelerin aynı işi yapması için gerekli olan tüm donanım aynı tutulmuş olup geriye sadece motor farklılığından ortaya çıkacak olan enerji tüketim farklılıkları gözlemlenmiştir.

Enerji tasarrufunun gözlenmesiyle alakalı testler yapılırken her iki sistem arasında birim çevrim sürelerinde çok fazla bir fark gözlenmemiştir. Fakat yapılan her bir çevrim sürelerine karşlık bir malzeme çıkmakta olup, makine günlük haftalık vb. testlere tabi tutulduğunda enerji konusunda Çizelge 2'de görüldüğü gibi \%13,98 oranında bir enerji tasarrufu elde edilmiştir. Değişken debili sistemde, pres makinasının ihtiyaç duyduğu anlarda gerekli debi ve basıncı üretmek için servo motor devreye girmektedir. Değişken debili sistem pres makinasının boşta bekleme sürelerinde motor tarafında enerji tüketimini sıfıra düşürmektedir. Bu durum makinanın uzun yıllar kullanılacağı göz önünde bulundurulursa ciddi maddi kayıpların önüne geçmektedir.

Çizelge 1. İki farklı hidrolik pres için ortak test parametreleri

Table 1. Common test parameters for two different hydrolic presses

\begin{tabular}{|c|c|}
\hline \multicolumn{2}{|c|}{ Koç ve Pot Tablalarının Almış Olduğu Yol Mesafeleri } \\
\hline Koç Tabla Hızlı İniş Mesafesi & $200 \mathrm{~mm}$ \\
\hline Koç Tabla Presleme Mesafesi & $80 \mathrm{~mm}$ \\
\hline Koç ve Pot Tabla Sıvama Mesafesi & $80 \mathrm{~mm}$ \\
\hline Koç Tabla Alınan Toplam Mesafe & $360 \mathrm{~mm}$ \\
\hline \multicolumn{2}{|c|}{ Test Süreleri } \\
\hline Birim İş Adedi Boyunca Geçen Süre & $18.8-18.9 \mathrm{sn}$ \\
\hline Malzemeyi Alma ve Yerleştirme Süresi & $11.38-11.49 \mathrm{sn}$ \\
\hline Test Boyunca Geçen Toplam Süre & $20 \mathrm{dk}$ \\
\hline Koç ve Pot Tablalarının Sıvama Esnasındaki Basınç Değerleri ve Toplam İş Adedi \\
\hline Koç Tablasının Basınç Değeri & $40-42$ Bar \\
\hline Pot Tablasının Basınç Değeri & 101 Bar \\
\hline Toplam İş Adedi & 40 Adet \\
\hline
\end{tabular}

Çizelge 2. İki Farklı Hidrolik Pres İçin Harcanan Enerji Değerleri Table 2. EnergyConsumption Values For Two Different Hydraulic Presses

\begin{tabular}{|c|c|c|}
\hline Enerji Ölçüm Değerleri & $\begin{array}{c}\text { Bulanık Kontrollü } \\
\text { Sabit Debili Pres }\end{array}$ & $\begin{array}{c}\text { Servo Tahrikli } \\
\text { Değişken Debili Pres }\end{array}$ \\
\hline Test Bitiminde Elde Edilen Son Değer & $361,3 \mathrm{kWh}$ & $153,8 \mathrm{kWh}$ \\
\hline Teste Başlamadan Önceki İlk Değer & $323,4 \mathrm{kWh}$ & $121,2 \mathrm{kWh}$ \\
\hline İki Değer Arasında Elde Edilen Fark & $37,9 \mathrm{kWh}$ & $32,6 \mathrm{kWh}$ \\
\hline Birim İş Adedi Boyunca Harcanan Enerji & $0,948 \mathrm{kWh} /$ Adet & $0,815 \mathrm{kWh} / \mathrm{Adet}$ \\
\hline
\end{tabular}

Her iki sistemin gürültü seviyesinin zamana bağlı ölçüm değerleri Çizelge 3’te verilmektedir. Her iki makine için ses ve gürültü seviyesi ölçümleri, ölçüm cihazıyla makinanın ön ve arka taraflarından makinaya 1 metre mesafeden 20 saniye boyunca yapılmıştır. Böylece; her iki sisteminde bir iş çevrimi 
süresi boyunca kaç $\mathrm{dB}$ ses seviyesinde çalıştı̆̆ 1 zamana bağlı olarak kaydedilmiştir. Yapılan hesaplamalar sonucu elde edilen değerlerden anlaşılacağı gibi ses ve gürültü seviyelerinde \%6 gibi bir azalma olduğu gözlemlenmiştir. Bu test makinalarının, bulunduğu ortamdan daha yalıtılmış bir ortamda diğer ortam gürültülerinden arındırılmış bir şekilde ses ve gürültü seviyesi testleri yapılmış olsaydı daha farklı sonuçlar alınabilirdi. Ayrıca, her iki pres için tablaların çalışma aşamalarındaki almış olduğu mesafeler aynı tutulup tablaların işlem hızları endüstriyel PC aracılığıyla Çizelge 4 ve Çizelge 5 'de verildiği gibi kaydedilmiştir.

Çizelge 3. Bulanık kontrollü sabit debili pres ve servo tahrikli değişken debili pres için gürültü ölçümleri Table 3. Noise Measurements for Fuzzy Controlled Constant Flow Press and Servo Driven Variable Flow Press

\begin{tabular}{|c|c|c|c|c|}
\hline $\begin{array}{c}\text { Zaman } \\
\text { (sn) }\end{array}$ & $\begin{array}{c}\text { Bulanık Kontrollü Sabit Debili Pres } \\
\text { Ön Taraf } \\
\text { Ölçümü (dB) }\end{array}$ & $\begin{array}{c}\text { Arka Taraf } \\
\text { Ölçümü (dB) }\end{array}$ & $\begin{array}{c}\text { Ön Taraf Ölçümü Tahrikli Değisen Debili Pres } \\
\mathbf{( d B )}\end{array}$ & $\begin{array}{c}\text { Arka Taraf } \\
\text { Ölçümü (dB) }\end{array}$ \\
\hline 1. & 73,50 & 78,60 & 69,09 & 73,88 \\
\hline 2. & 72,90 & 77,10 & 68,53 & 72,47 \\
\hline 3. & 69,60 & 73,70 & 65,42 & 69,28 \\
\hline 4. & 69,20 & 74,10 & 65,05 & 69,65 \\
\hline 5. & 70,00 & 73,60 & 65,80 & 69,18 \\
\hline 6. & 68,80 & 73,40 & 64,67 & 69,00 \\
\hline 7. & 70,50 & 73,90 & 66,27 & 69,47 \\
\hline 8. & 72,50 & 74,10 & 68,15 & 69,65 \\
\hline 9. & 70,50 & 75,50 & 66,27 & 70,97 \\
\hline 10. & 71,00 & 75,00 & 66,74 & 70,5 \\
\hline 11. & 71,50 & 75,30 & 67,21 & 70,78 \\
\hline 12. & 70,50 & 75,70 & 66,27 & 71,16 \\
\hline 13. & 70,90 & 74,10 & 66,65 & 69,65 \\
\hline 14. & 68,90 & 73,60 & 64,77 & 69,18 \\
\hline 15. & 76,90 & 79,80 & 72,29 & 75,01 \\
\hline 16. & 75,40 & 80,20 & 70,88 & 75,39 \\
\hline 17. & 70,40 & 76,00 & 66,18 & 71,44 \\
\hline 18. & 69,70 & 72,90 & 65,52 & 68,53 \\
\hline 19. & 68,90 & 72,20 & 64,77 & 67,87 \\
\hline 20. & 65,00 & 74,50 & 61,10 & 70,03 \\
\hline Maksimum & 76,90 & 80,20 & 72,29 & 75,39 \\
\hline & & & & \\
\hline
\end{tabular}

Servo motorun sürücü üzerinden hız ve tork gibi kazanç değer parametreleri, sistemin gözle görülür daha sağlıklı çalışması durumu için denenerek gerekli değere set edilmiştir. Tablaların çalışma hızındaki verimliliği gözlemlendiğinde aynı işi değişken debili sistem 15,4 saniye gibi bir çevrim süresinde yaparken, klasik sistem ise 18,8-18,9 saniye gibi bir çevrim süresinde yerine getirmektedir. Değişken debili sistem verilere göre \%18 oranında daha hızlı ve kararlı çalıştığı gözlemlenmiştir. Servo motorun sistemde ani kalkışlarda zorlu yük durumlarına daha çabuk adapte olduğu ve motorda yığılma olmadan gerekli torku üretmesi, gereken devri çok daha kısa bir sürede alması çalışma hızındaki verimliliğe etkisi olduğu görülmektedir. 
Çizelge 4. Bulanık kontrollü sabit debili pres için çalışma hızı verimliliği test verileri Table 4. Working speed efficiency test data for fuzzy controlled constant flow press

\begin{tabular}{|c|c|c|c|}
\hline $\begin{array}{c}\text { Koç ve Pot Tablalarının Almış } \\
\text { Olduğu Yol Mesafeleri }\end{array}$ & 1.Deneme & 2.Deneme & 3.Deneme \\
\hline Koç Tabla Hızlı İniş Mesafesi & $200 \mathrm{~mm}$ & $200 \mathrm{~mm}$ & $200 \mathrm{~mm}$ \\
\hline Koç Tabla Presleme Mesafesi & $80 \mathrm{~mm}$ & $80 \mathrm{~mm}$ & $80 \mathrm{~mm}$ \\
\hline Koç ve Pot Tabla Sıvama Mesafesi & $80 \mathrm{~mm}$ & $80 \mathrm{~mm}$ & $80 \mathrm{~mm}$ \\
\hline Koç Tabla Alınan Toplam Mesafe & $360 \mathrm{~mm}$ & $360 \mathrm{~mm}$ & $360 \mathrm{~mm}$ \\
\hline Koç ve Pot Tablalarının Hız & & & \\
Değerleri & & & \\
\hline Koç Tabla Aşağıya İniş Hızı & $130 \mathrm{~mm} / \mathrm{sn}$ & $130 \mathrm{~mm} / \mathrm{sn}$ & $130 \mathrm{~mm} / \mathrm{sn}$ \\
\hline Koç Tabla Presleme Hızı & $16 \mathrm{~mm} / \mathrm{sn}$ & $16 \mathrm{~mm} / \mathrm{sn}$ & $16 \mathrm{~mm} / \mathrm{sn}$ \\
\hline Koç Tabla Yukarıya Çıkış Hızı & $200 \mathrm{~mm} / \mathrm{sn}$ & $200 \mathrm{~mm} / \mathrm{sn}$ & $200 \mathrm{~mm} / \mathrm{sn}$ \\
\hline Pot Tabla Yukarıya Çıkış Hızı & $42 \mathrm{~mm} / \mathrm{sn}$ & $42 \mathrm{~mm} / \mathrm{sn}$ & $42 \mathrm{~mm} / \mathrm{sn}$ \\
\hline Sıvama esnasında Koç Tabla Basıncı & $29 \mathrm{Bar}$ & $37 \mathrm{Bar}$ & $45 \mathrm{Bar}$ \\
\hline Sivama esnasında Pot Tabla Basıncı & $73 \mathrm{Bar}$ & $91 \mathrm{Bar}$ & $125 \mathrm{Bar}$ \\
\hline Birim Çevrim Süresi & $18.8 \mathrm{sn}$. & $18.8 \mathrm{sn}$. & $18.9 \mathrm{sn}$. \\
\hline
\end{tabular}

Çizelge 5. Servo tahrikli değişken debili pres için çalışma hızı verimliliği test verileri Table 5. Working speed efficiency test data for servo driven variable flow press

\begin{tabular}{|c|c|c|c|}
\hline $\begin{array}{c}\text { Koç ve Pot Tablalarının Almış } \\
\text { Olduğu Yol Mesafeleri }\end{array}$ & 1.Deneme & 2.Deneme & 3.Deneme \\
\hline Koç Tabla Hızlı İniş Mesafesi & $200 \mathrm{~mm}$ & $200 \mathrm{~mm}$ & $200 \mathrm{~mm}$ \\
\hline Koç Tabla Presleme Mesafesi & $80 \mathrm{~mm}$ & $80 \mathrm{~mm}$ & $80 \mathrm{~mm}$ \\
\hline Koç ve Pot Tabla Sıvama Mesafesi & $80 \mathrm{~mm}$ & $80 \mathrm{~mm}$ & $80 \mathrm{~mm}$ \\
\hline Koç Tabla Alınan Toplam Mesafe & $360 \mathrm{~mm}$ & $360 \mathrm{~mm}$ & $360 \mathrm{~mm}$ \\
\hline Koç ve Pot Tablalarının Hız & & & \\
Değerleri & & & \\
\hline Koç Tabla Aşağıya İniş Hızı & $160 \mathrm{~mm} / \mathrm{sn}$ & $160 \mathrm{~mm} / \mathrm{sn}$ & $160 \mathrm{~mm} / \mathrm{sn}$ \\
\hline Koç Tabla Presleme Hızı & $20 \mathrm{~mm} / \mathrm{sn}$ & $20 \mathrm{~mm} / \mathrm{sn}$ & $20 \mathrm{~mm} / \mathrm{sn}$ \\
\hline Koç Tabla Yukarıya Çıkış Hızı & $250 \mathrm{~mm} / \mathrm{sn}$ & $250 \mathrm{~mm} / \mathrm{sn}$ & $250 \mathrm{~mm} / \mathrm{sn}$ \\
\hline Pot Tabla Yukarıya Çıkış Hızı & $50 \mathrm{~mm} / \mathrm{sn}$ & $50 \mathrm{~mm} / \mathrm{sn}$ & $50 \mathrm{~mm} / \mathrm{sn}$ \\
\hline Sivama esnasında Koç Tabla Basıncı & $22 \mathrm{Bar}$ & $35 \mathrm{Bar}$ & $43 \mathrm{Bar}$ \\
\hline Sivama esnasında Pot Tabla Basıncı & 50 Bar & $82 \mathrm{Bar}$ & $103 \mathrm{Bar}$ \\
\hline Birim Çevrim Süresi & $15.4 \mathrm{sn}$. & $15.4 \mathrm{sn}$. & $15.4 \mathrm{sn}$. \\
\hline
\end{tabular}

\section{SONUÇ ve TARTIŞMALAR (RESULTS and DISCUSSIONS)}

$\mathrm{Bu}$ çalışmada, sanayi uygulamalarında kullanılan sabit ve değişken debili pres makineleri için gereken mühendislik hesaplamalarının ve ARGE süreçlerinin yapılmasından sonra en optimum şekilde makinelerin üretimi sağlanmaya çalışılmıştır. Ayrıca bulanık mantık kontrol algoritmaları ile basınç kontrol döngüleri iyileştirilmeye çalışılmıştır.

Çalışma sonunda; bulanık mantık denetleyici, PLC içerisine Min-Max çıkarım yöntemi, ağırlık ortalaması yöntemine göre gerçekleştirilen durulaştırma, çıkış yüzdesinin elde edildiği yazılım ile entegre edilmiştir. Eklenen bu yazılım ile sistem basıncının daha optimum sonuçlar ile kontrolünün yapılması sağlanmıştır. Ayrıca, endüstri 4.0 teknolojilerinden olan RFID, IO-LİNK, Titreşim-Sıcaklık Sensörü gibi özel uygulamalar Hidrolik Pres Makinelerine uygulanarak sisteme esneklik ve avantaj sağlanmıştır. Geliştirilen servo tahrikli sistem ile klasik hidrolik pres arasında enerji verimliliği, ses (gürültü) seviyesi verimliliği ve çalışma hızındaki verimlilikler çeşitli test ve analizler yapılarak ortaya konulmuş, servo sistemin klasik sisteme göre farklılıkları ön plana çıkarılmıştır. Yapılan bu test ve 
analizler sonucunda enerji tasarrufunda \%13.98, ses (gürültü) azaltımında \%6, çalışma hızında \%18 oranında verimlilik elde edildiği çizelgelerde anlatılmıştır.

$\mathrm{Bu}$ çalışmada kullanılan ve anlatılan yöntemlerin birçok hidrolik sisteme uyarlanabileceği görülmektedir. Elde edilen sonuçlardan yapılan çalışmanın, diğer çalışmalara temel olabileceğini, bulunan sonuçların geliştirmeye açık olduğunu, anlatılan özelliklerin benzer çalışmalara ve literatüre ışık tutacağını söylemek mümkündür.

\section{KAYNAKLAR (REFERENCES)}

Altaş, İ.H., 1999, “Bulanık Mantık: Bulanıklılık Kavramı”, Enerji Elektrik Elektromekanik-3e,Temmuz 1999, Sayı 62, 80-85 s, Bilesim Yayıncılık A. Ş.

Aydoğmuş, Z., 2009, "Implementation Of A BM-Based Level Control Using SCADA", Expert Systems With Applications 36 pp. 6593-6597.

Bostan B. 2011, VI. Ulusal hidrolik pnömatik kongresi ve sergisi (HPKON) “Değişken hızlı pompa tahrik sistemleri “.

Da Ruan and van der Wal, A., 1998, "Controlling The Power Output Of A Nuclear Reactor with Fuzzy Logic", Information Sciences 110, pp.151-177.

Elmas, Ç., 2007, "Yapay Zeka Uygulamaları", Seçkin Yayıncılık, 230-257 s.

Karakuzu, C. ve Öztürk, S., 2013, "PLC İle BM Tabanlı Hata Düzeltmeli Üç Fazlı Motor Hız Kontrolü" emo.org.trekler/f0442558302a6ed_ek.pdf..

Kaynak, Okyay ve Armağan, Gülçin, 1993, "Bulanık Denetim ve Endüstriyel Uygulamaları”, Tübitak Marmara Araştırma Merkezi, 29 Ocak 1993.

Kılıç, K. ve Tanrıkulu Z., 2017, “Yönetim Bilişim Sistemleri Yüksek Lisans Dersi”, IÜ FBE Enformatik Ana Bilim Dalı.

Özçalık, H. R., Türk, A., Yıldız, C., Koca, Z., 2008, “Katı Yakıtlı Buhar Kazanında Yakma Fanının BM Denetleyici İle Kontrolü", KSÜ Fen ve Mühendislik Dergisi, 11(1).

Özdemir, M. T. ve Orhan, A., 2012, “An Experimental System For Electrical And Mechanical Education: Micro Hydro Power Plant Prototype", Procedia - Social and Behavioral Sciences 47, pp. 2114 2119.

Saad, N. and Arrofiq, M., 2011, “A PLC-Based Modified-Fuzzy Controller For PWM Driven induction Motor Drive With Constant V/Hz Ratio Control", Robotics and Computer-Integrated manufacturing 28, pp. 95-112, 2012.

Selek, A., 2017, “Endüstri Tarihine Kısa Bir Yolculuk”, Endüstri 4.0 Platformu, http://www.endustri40.com/ adresinden alındı.

Sinecen, M. ve Özek, A., 2002, “Klima Sistem Kontrolünün Bulanık Mantık İle Modellenmesi”, PAÜ Fen Bilimleri Enstitüsü, 06 Eylül 2002.

Yılmaz, S., Cakir B., Gedik, A., Dinçer, H., 1999, “Speed Control Of A Conveyor System By Means Of Fuzzy Control Aided PLC", IEEE, ISIE'99 Bled, Slovenia, pp. 1328-1332.

Zadeh, A. Lotfi, 1971, “On Fuzzy Algorihtms”, Electron. Res. Lab., Univ. California, Berkeley, Memo. M325. 